\title{
The Effect of Trimipramine on Sleep in Patients with Major Depressive Disorder
}

\author{
M. Wiegand, M. Berger, J. Zulley, D. von Zerssen \\ Max-Planck-Institute of Psychiatry, Munich, FRG
}

\begin{abstract}
Antidepressants generally inhibit REM sleep. This effect is of ten considered to be a crucial feature of these drugs. Trimipramine, however, is a tricyclic antidepressant which does not inhibit REM sleep in rats (Khazan and Brown, 1970; Wasserman and Khazan, 1971). This result could be confirmed in man: Dunleavy et al. (1972) administered this drug to two healthy volunteers and found no alteration of REM sleep. In our present study we examined the action of trimipramine on sleep in patien ts with major depressive disorder. We were especially interested in the effect on REM sleep parameters. In order to elucidate the mode of action of this 'drug, we investigated, in addition, the question of whether the effect of trimipramine on prolactin, human growth hormone, and cortisol resembled that of other antidepressants.
\end{abstract}

\section{Methods \\ We examined 10 patients ( 2 male, 8 female) with the diagnosis of a major depressive disorder according to the RDC; 7 of them ( 1 male, 6 female) fulfilled the criteria for the endogenous subtype. The mean age was $43.0 \pm 13.3$ years, the mean score in the Hamilton Depression Scale $(21$ items) before treatment was $23.8 \pm 5.2$. All patients were free from any psychoactive medication, except chlo- raldurate, for at least seven days before sleep recordings took place. Af- ter an adaptation night, sleep was recorded in the night preceding the first medication and in the 2 nd, 11 th, and 21 st nights of treatment. We administered $75 \mathrm{mg}$ trimipramine on the first day and $100 \mathrm{mg}$ on the second day. The dose was augmented stepwise, and from the 6th day on the patients received $200 \mathrm{mg}$ per day.}

Ratings of depressive symptomatology were performed by means of the Hamilton Depression Scale (21 items) on the days before each sleep recording.

In an additional study with healthy subjects, we examined the effect of trimipramine on neuroendocrine parameters. We administered a single oral dose of $75 \mathrm{mg}$ trimipramine to 8 healthy volunteers ( 5 male, 3 female); the mean age was $25.1 \pm 4.4$ years. Blood samples were taken at half-hour intervals, two of them before and six after the administration of the drug. Prolactin, human growth hormone, and cortisol were measured by radioimmunoassay.

\section{Results}

\section{Sleep EEG}

Table 1 summarizes the effect of trimipramine on several sleep parameters. From the 11 th day on, sleep period time and sleep efficiency are significantly increased, and sleep latency is shortened. There is no influence on slow wave sleep. REM sleep time is significan tly increased with regard to the mean baseline score (which, however, appears to be abnormally low in our sample). The first REM period is lengthened in the beginning of treatment. REM latency is significantly longer on the 11 th day only. There seems to be no effect on REM density.

\section{Psychopathology}

Taking a reduction of at least $50 \%$ of the baseline Hamilton score as a response criterion, 5 patients ( 3 endogenous and 2 non-endogenous) responded to treatment with trimipramine. The improvement is most clearly reflected by the changes in the insomnia and anxiety items. This finding corresponds well with the results of the sleep recordings.

\section{Hormones}

Figure 1 demonstrates the effect of a single oral dose of $75 \mathrm{mg}$ trimipramine on the plasma levels of prolactin, human growth hormone and cortisol in healthy probands. There is a remarkable effect on the mean prolactin level: 6 of the 8 probands exhibit an increase of more than $100 \%$ of the baseline plasma prolactin level three hours after the administration of the drug. The plasma levels of human growth hormone and cortisol are not elevated (as the blood samplings took place in the afternoon, cortisol levels decline according to their usual circadian rhythm).

\section{Discussion}

In contrast to the REM suppressing action of antidepressant drugs in general, we found trimipramine to increase the percentage of REM sleep time. Regarding the abnormally low mean baseline score of this variable (which is due to a large proportion of patients with very severely disturbed sleep in our sample), this result could be interpreted as a normalization of REM sleep time, in accord with the general improvement of sleep during treatment. In some patients, there was even a stimulation of REM sleep beyond normal scores. Our findings, thus, support the results from other studies mentioned before that there is no REM suppressing effect of trimipramine, and even point to a REM stimulating effect of this drug.

This has some implications concerning the importance of REM sleep suppression for an tidepressant action. Studies by Gillin et al. (1978) and Kupfer et al. (1980) which show a correlation between the initial REM suppression of a drug and its antidepressant effect and Vogel's $(1975,1980)$ experiments which demonstrate that the antidepressant effect of REM sleep deprivation support the hypothesis that REM suppression is an important factor, or even a prerequisite, 
Table 1 Słeep parameters: mean scores and standard deviations; Significant changes from baseline: * $p \leqslant 0.05, * * \leqslant 0.01$ (Wilcoxon's test, two-tailed)

\begin{tabular}{|c|c|c|c|c|}
\hline & Baseline & $\begin{array}{l}\text { 2nd day of } \\
\text { treatment }\end{array}$ & $\begin{array}{l}11 \text { th day of } \\
\text { treatment }\end{array}$ & $\begin{array}{l}21 \text { st day of } \\
\text { treatment }\end{array}$ \\
\hline Sleep period time & $347.8 \pm 103.6$ & $397.8 \pm 41.3$ & $405.4 \pm 42.2^{*}$ & $414.3 \pm 25.8^{\star}$ \\
\hline Sleep efficiency & $69.2 \pm 30.6$ & $86.0 \pm 9.7$ & $88.2 \pm 9.8^{*}$ & $90.1 \pm 9.1 *$ \\
\hline Sleep latency & $46.4 \pm 73.5$ & $22.3 \pm 22.7$ & $15.4 \pm 14.7^{*}$ & $12.8 \pm 6.9^{4}$ \\
\hline $\begin{array}{l}\text { Slow wave sleep } \\
\text { time }(\%)\end{array}$ & $12.4 \pm \quad 12.8$ & $7.7 \pm 9.8$ & $11.3 \pm 12.1$ & $8.5 \pm 8.5$ \\
\hline REM sleep time $(\%)$ & $14.3+5.3$ & $22.9 \pm 4.8^{*}$ & $19.6 \pm 3.4^{*}$ & $20.9 \pm 5.3^{*}$ \\
\hline REM latency & $44.8 \pm 31.0$ & $38.8 \pm 39.6$ & $70.2 \pm 34.1$ & $56.0 \pm 20.3$ \\
\hline $\begin{array}{l}\text { Duration of } \\
\text { 1st REM period }\end{array}$ & $12.3 \pm 10.6$ & $30.9 \pm 19.9^{*}$ & $23.7 \pm 16.9$ & $19.7 \pm 17.6$ \\
\hline REM density & $34.5 \pm 11.1$ & $32.3 \pm 11.8$ & $41.3 \pm 13.3$ & $38.4 \pm 10.1$ \\
\hline
\end{tabular}

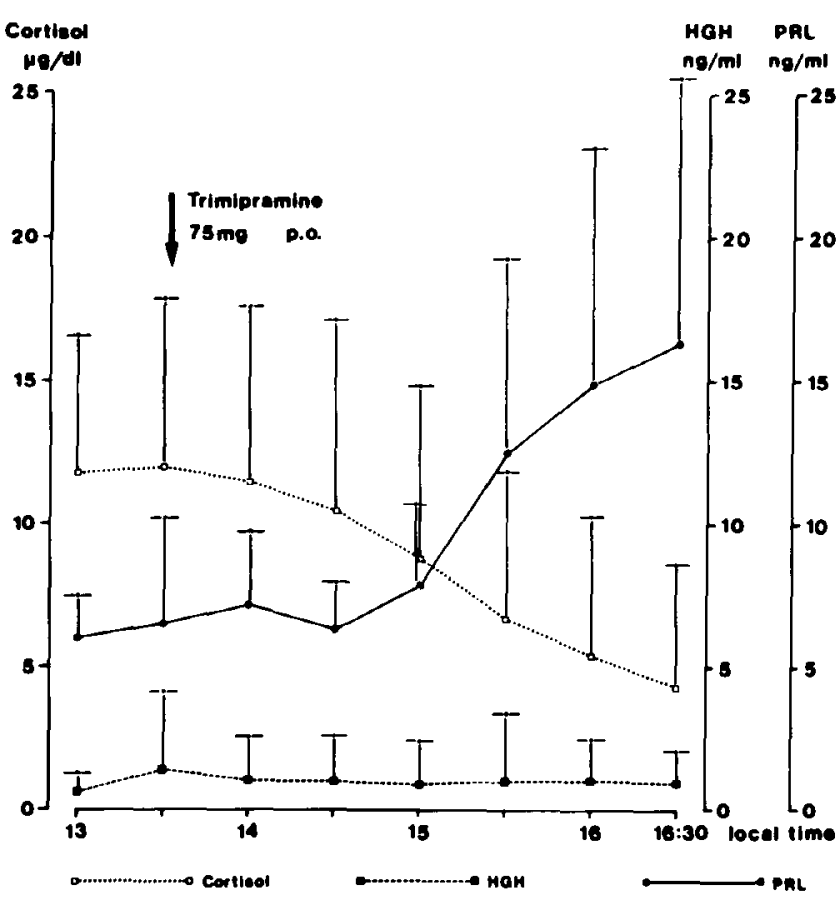

Fig. 1 Effect of a single oral dose of $75 \mathrm{mg}$ trimipramine on plasma levels of prolactin, human growth hormone and cortisol in healthy probands.

for antidepressant action. Our results seem to contradict this hypothesis.

The absence of REM sleep suppression during acute treatment with trimipramine suggests that the mode of action of this drug may be different from that of other antidepressants. Several pharmacological studies demonstrate more atypical features of this drug. There is no effect on betaadrenergic receptors (Hauser et al., 1985), only a very weak effect on norepinephrine and serotonine re-uptake in the rat (Richelson and Pfenning, 1984), and no effect on amine re-uptake in man (Gastpar, personal communication). Waldmeier (1982) demonstrated a dopamine receptor blocking property of trimipramine. Our findings concerning the effect on prolactin, human growth hormone, and cortisol also reveal an atypical response pattem in comparison with other antidepressants. It rather resembles that of neu- roleptics. There are several other similarities to neuroleptic drugs, and the observed clinical effect of trimipramine has some features in common with those of some sedative neuroleptics, e. g. levomepromazine which has the same side chain as trimipramine, and thioridazine which stimulates REM sleep, according to Kales et al. (1974). Both these drugs are reported to have an antidepressant action besides the neuroleptic one. Trimipramine resembles them in possessing thymoleptic properties without being a typical antidepressant. This is compatible with the assumption that certain sedative neuroleptics may be useful in the treatment of depressive disorders.

\section{References}

Dunleavy, D. L. F., V. Brezinova, I. Oswald, A. W. Maclean, M. Tinker: Changes during weeks in effects of tricyclic drugs on the human sleeping brain. Brit. J. Psychiat. 120 (1972) 663-672

Gillin, J. C., R. J. Wyatt, D. Fram, F. Snyder: The relationship between changes in REM sleep and clinical improvement in depressed patients treated with amitriptyline. Psychopharmacology 59 (1978) $267-272$

Hauser, K., H. R. Olpe, R. S. G. Jones: Trimipramine, a tricyclic antidepressant exerting atypical actions on the central noradrenergic system. Eur. J. Pharmacol. 111 (1985) 23-30

Kales, A., M. B. Scharf, J. D. Kales, E. O. Bixler, M. Djoko: Sleep laboratory drug evaluation: thioridazine (mellaril), a REM enhancing drug. In: Sleep research, ed. by M. H. Chase, W. C. Stern, P. L. Walter. Brain Information Service/Brain Research Institute, University of California, Los Angeles 1974, Vol. 3, 55

Khazan, N., P. Brown: Differential effects of three tricyclic antidepressants on sleep and REM sleep in the rat. Life Sci. 9 (1970) 279-284

Kupfer, D. J., D. G. Spiker, P. A. Coble, J. F. Neil, R. Ulrich, D. H. Shaw: Depression, EEG sleep, and clinical response. Comp. Psychiatry 21 (1980) 212-220

Richelson, E., M. Pfenning: Blockade by antidepressants and related compounds of biogenic amine uptake into rat brain synaptosomes: most antidepressants selectively block norepinephrine uptake. Eur. J. Pharmacol. 104 (1984) 277-286

Vogel, G. W., A. Thurmond, P. Gibbons: REM sleep reduction effects on depression syndromes. Arch. Gen. Psychiatry 32 (1975) 765-777

Vogel, G. W., F. Vogel, R. S. McAbee, A. J. Thurmond: Improvement of depression by REM sleep deprivation. Arch. Gen. Psychiatry 37 (1980) 247-253

Waldmeier, $P$. C.: Effects of antidepressant drugs on dopamine uptake and metabolism. J. Pharm. Pharmacol. 34 (1982) 391

Wasserman, A., N. Khazan: Effects of chronic treatment with imipramine, desipramine and trimipramine on REM sleep in the rat. Pharmacologist 13 (1971) 255 